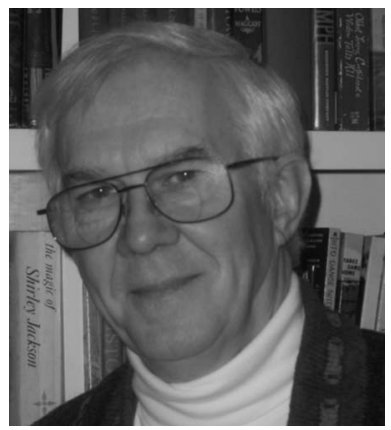

\section{Web-based Journalism}

My inexpensive glasses from CVS are getting a workout these days and they will probably see more use in the future. The signs are there. U. S. News and World Report as well as the Christian Science Monitor are converting to an electronic format. They will be joining a number of city papers that have already made the jump.

It's hard to believe that not too many years ago we were amazed and amused by a new type of computer application, the browser. When you fired up Netscape you could find things that would have taken a trip to the library a few months before. Search was usually done on Alta Vista until Google came along. And there was this amazing online bookstore called Amazon.com.

Now, we spend much of our time before a computer. This journal is administered, read, and distributed on the Web. It is a good bet that you are reading this piece on a display screen. I doubt there are many optical engineers who open the printed version.

Indeed, much of what SPIE does involves use of the Web. Currently, it provides the interfaces to conferences and publications and it is experimenting with delivering courses through live feeds. And there may be other approaches to be explored.

But there are other means of Web communications. There are many discussion groups that revolve around work or hobbies. They tend to work well when there is a need to understand specific areas (e.g., software applications) or to express opinions. While I was president of SPIE, I spearheaded an effort to establish Web discussion groups. Although it started fairly well, it dwindled from lack of interest. For such groups to thrive an involved moderator is needed to drive the discussion.

Where do my interests lie? Looking at the RSS feeds on my newsreader, I find that they group into four areas: family blogs, computer technology (with an emphasis on Apple), Aperture, a photography application, and some odds and ends, such as Paul Krugman's blog in the New York Times, the Boston Globe's Big Picture (an exquisite photography site), and the diary of Samuel Pepys (the entry for the same day, 343 years ago).

Where does the Web go from here? There is a concept called Web 2.0, wherein the content comes from the par- ticipation of people using social applications such as Facebook, Flickr, LinkedIn, and MySpace. These browserbased applications usually have a friendly interface based on minimal navigation, but they can demand much time and erode one's privacy.

But the future of the Web should not stop at communal naval gazing. One of the most interesting blogs begun during the recent U.S. presidential campaign was fivethirtyeight.com. The name of the site comes from the number of votes in the Electoral College. The site was devoted to an educated aggregation and analysis of the polls of the presidential and congressional races conducted during the recent U.S. elections. There are other Web sites [e.g., Pollster.com, the Princeton Election Consortium (election.princeton.edu), and RealClearPolitics.com] that provide voters with tools to understand the welter of polls.

The creator of the fivethirtyeight.com, Nate Silver, is a statistician for Baseball Prospectus, a statistical firm that analyzes baseball team prospects based on the records of different potential rosters. On the political Web site he uses an approach that analyzes the polls, weights them based on currency, past performance, and political bias, and then produces a prediction based on this composite. During the Iowa primaries, Silver predicted that Barack Obama would win Iowa from Hillary Clinton in the Democratic primaries when most other analysts had Clinton as the winner.

This could be pretty dry stuff, although the recent presidential race certainly provided enough suspense because of the many uncertainties that presented themselves during the campaign. But the site distinguished itself by combining Silver's thoughtful poll analysis with a series of sympathetic reports by Sean Quinn, a California journalist, and photo galleries by Brett Marty, a documentary filmmaker based in San Francisco. The pair documented the election efforts in various states, known in politics as "the ground game."

Most of these reports described the activity at the presidential campaign offices, giving the reader a feel for the work done in the offices and the morale. They also observed early voting turnouts in the areas. One particularly affecting report on voting described an elderly black man voting in North Carolina. I tried to read Quinn's text 
to my wife, but failed and let her read it for herself. We were both in tears. The report can be found at http:// www.fivethirtyeight.com/2008/10/on-road-raleigh-northcarolina.html. This admixture of analysis and reporting caused me to return to the site several times a day.

There may be comparable sites exploring other aspects of life using this type of Web-based journalism, but I don't know any. The closest I can come to such reporting is a book, Let Us Now Praise Famous Men. It describes a trip that the author, James Agee, and photographer, Walker Evans, took through the South in 1936 in the depth of the depression on behalf of Fortune, the business magazine of the Luce empire (Time, Life, etc.). The piece was rejected. Agee then published it as a book in 1941, but it sold only 600 copies. Through Agee's beautiful prose and Evans' candid images, it chronicles the lives of a group of white families in Alabama. It has been a favorite of mine for years. It was reissued in 2001.

Are there other aspects of current life that would benefit from such compelling and focused journalism? There are many websites devoted to a myriad of interests, but most are neglected-scraps of debris caught in the Web. It takes, as is evident at fivethirtyeight.com, a devotion to getting things right. Although Silver was a strong supporter of Barack Obama, he analyzed the polls as a professional statistician in much the same way that an engineer addresses particularly nasty and costly redesign-as it is and not as he or she would like it to be.

Could there be similar Web-based journalism devoted to technical topics? Consider that the rate of change of progress in many areas of technology is exceptionally rapid today. Someone might establish a Web site that posts a series of interviews with engineers working in a hot field and provides references to their papers. Questions might be posed regarding where the field is heading and what are the greatest barriers to progress. The subjects of these interviews would be those in the trenches. Over the years, SPIE has tried to address the problem of getting information from engineers, who have no incentive to publish in archival journals. And yet, they and their peers need to know what's outside their own trench.

This journal publishes peer-reviewed technical news. In this era of YouTube and Flickr and compelling Web sites like fivethirtyeight.com, we should consider some effort to go to the engineers and find out what's happening. With web cameras like the iSight and QuickCam, interviews conducted remotely and lab tours could be contributed by the interviewers. By posting the reports a continuing basis, a long-range dialog between researchers may be established without waiting for a publication cycle to finish.

I don't know whether I will find a site as compelling as fivethirtyeight.com was during the recent elections. As one browser put it: "Thanks for making my last few weeks terribly unproductive as I obsessively check this site all day for your work." Considering the state of the economy right now, maybe I'll reread Agee's book to remind me how much things have changed as we contend with our current recession.

\section{Donald C. O'Shea}

Editor 